\title{
Article \\ Alterations in Leptin Signaling in Amyotrophic Lateral Sclerosis (ALS)
}

\author{
Agueda Ferrer-Donato ${ }^{1,+}{ }^{\text {, Ana Contreras }}{ }^{2,+}{ }^{(D)}$, Laura M. Frago ${ }^{3,4}$ (D) , Julie A. Chowen ${ }^{3,4,5}$ (D) \\ and Carmen M. Fernandez-Martos 1,6,*(D) \\ 1 Research Unit of the National Hospital of Paraplegics (UDI-HNP), Finca La Peraleda s/n, \\ 45007 Toledo, Spain; aferrerd@externas.sescam.jccm.es \\ 2 Health Research Centre (CEINSA), University of Almeria (UAL), Carr. Sacramento, s/n, \\ 04120 Almeria, Spain; Acm699@ual.es \\ 3 Department of Pediatrics and Pediatric Endocrinology, Hospital Infantil Universitario Niño Jesús, Instituto de \\ Investigación la Princesa, Universidad Autónoma de Madrid, 28009 Madrid, Spain: \\ laura.frago@uam.es (L.M.F.); julieann.chowen@salud.madrid.org (J.A.C.) \\ 4 Centro de Investigación Biomédica en Red Fisiopatología de la Obesidad y la Nutrición (CIBEROBN), \\ Instituto de Salud Carlos III, 28029 Madrid, Spain \\ 5 IMDEA Food Institute, CEI UAM + CSIC, 28048 Madrid, Spain \\ 6 Wicking Dementia Research and Education Centre, College of Health and Medicine, University of Tasmania, \\ Hobart 7001, Australia \\ * Correspondence: cmfernandezm@sescam.jccm.es or Carmen.fernandezmartos@utas.edu.au; \\ Tel.: +34-925-247789; Fax: +34-925-247745 \\ + These authors are both first authors.
}

check for updates

Citation: Ferrer-Donato, A.; Contreras, A.; Frago, L.M.; Chowen, J.A.; Fernandez-Martos, C.M. Alterations in Leptin Signaling in Amyotrophic Lateral Sclerosis (ALS). Int. J. Mol. Sci. 2021, 22, 10305. https://doi.org/10.3390/ ijms221910305

Academic Editors: Marcello Ciaccio and Luisa Agnello

Received: 9 August 2021

Accepted: 21 September 2021

Published: 24 September 2021

Publisher's Note: MDPI stays neutra with regard to jurisdictional claims in published maps and institutional affiliations.

Copyright: (c) 2021 by the authors. Licensee MDPI, Basel, Switzerland. This article is an open access article distributed under the terms and conditions of the Creative Commons Attribution (CC BY) license (https:// creativecommons.org/licenses/by/ $4.0 /)$

\begin{abstract}
Leptin has been suggested to play a role in amyotrophic lateral sclerosis (ALS), a fatal progressive neurodegenerative disease. This adipokine has previously been shown to be associated with a lower risk of ALS and to confer a survival advantage in ALS patients. However, the role of leptin in the progression of ALS is unknown. Indeed, our understanding of the mechanisms underlying leptin's effects in the pathogenesis of ALS is very limited, and it is fundamental to determine whether alterations in leptin's actions take place in this neurodegenerative disease. To characterize the association between leptin signaling and the clinical course of ALS, we assessed the mRNA and protein expression profiles of leptin, the long-form of the leptin receptor (Ob-Rb), and leptin-related signaling pathways at two different stages of the disease (onset and end-stage) in TDP-43 ${ }^{\mathrm{A} 315 \mathrm{~T}}$ mice compared to age-matched WT littermates. In addition, at selected time-points, an immunoassay analysis was conducted to characterize plasma levels of total ghrelin, the adipokines resistin and leptin, and metabolic proteins (plasminogen activator inhibitor type 1 (PAI-1), gastric inhibitory peptide (GIP), glucagon-like peptide 1 (GLP-1), insulin and glucagon) in TDP-43 ${ }^{\mathrm{A} 315 \mathrm{~T}}$ mice compared to WT controls. Our results indicate alterations in leptin signaling in the spinal cord and the hypothalamus on the backdrop of TDP-43-induced deficits in mice, providing new evidence about the pathways that could link leptin signaling to ALS.
\end{abstract}

Keywords: neurodegenerative disease; amyotrophic lateral sclerosis (ALS); metabolism; leptin; long leptin receptor (Ob-Rb); TAR DNA binding protein (TDP-43)

\section{Introduction}

Amyotrophic lateral sclerosis (ALS) is an irreversible neurodegenerative disorder characterized by the selective and progressive loss of upper and lower motor neurons of the cerebral cortex, brainstem, and spinal cord [1]. ALS is fast becoming a major health and socio-economic challenge for many countries around the world; however, no current therapeutic disease-modifying intervention exists. Although the cellular basis for neurodegeneration in ALS is not yet fully understood, numerous studies have shown that the underlying disease process involves multiple complex genetic and non-genetic factors, including metabolic alterations. 
Included amongst the underlying metabolic alterations in ALS is leptin, a polypeptide hormone secreted primarily by adipocytes that exerts an important role in regulating food intake and energy balance through actions in the brain [2,3]. Leptin acts by binding to its receptors that are structurally related to the cytokine receptor class I family. Alternative splicing generates distinct isoforms of the leptin receptor, including long $(\mathrm{Ob}-\mathrm{Rb})$ and short isoforms (Ob-Ra and Ob-Rc-f), with Ob-Rb being thought to transmit the majority of leptin's biological signals [4]. However, in addition to its classical role in the neuroendocrine regulation of food intake, the existence of its receptors in extra-hypothalamic brain regions strongly suggests that leptin affects other biological processes. Indeed, studies indicate that leptin is strongly involved in the central nervous system (CNS) $[5,6]$ and neurological disorders [7-9] through mechanisms of action involving its four major signal transduction pathways, Janus tyrosine kinase/signal transducer and activator of transcription (JAK/STAT), extracellular signal-regulated kinase pathway (ERK), phosphatidylinositol 3-kinase (PI3K)/ Akt, and mitogen-activated protein kinase (MAPK)/sirtuin 1 (SIRT1), downstream of $\mathrm{Ob}-\mathrm{Rb}$ receptors (King et al. 2018; Zhang and Chua, 2018). Leptin is reported to be involved in ALS [10]; however, our understanding of the underlying biological mechanisms of leptin's actions in the pathogenesis of ALS is limited, although both clinical and epidemiological studies support the concept that altered leptin levels contribute to the pathogenesis of ALS [11]. A recent epidemiological study determined that leptin levels are inversely associated with ALS outcome [12]; increasing leptin concentrations were associated with longer survival of ALS patients, which highlights the possible link between leptin and the clinical outcome of ALS. Altered peripheral levels of leptin have been recently reported in patients with ALS and frontotemporal dementia (FTD) [13], which exists on a continuous clinical spectrum with ALS [14]. Interestingly, new epidemiological data suggest that increased dietary fat intake (high-fat diet; HFD), which significantly increases leptin levels, may reduce the risk of developing ALS [15-17]. A positive correlation between plasma leptin and body mass index (BMI) was observed in ALS patients [11]. Nevertheless, a study in SOD1 ${ }^{\mathrm{G} 93 \mathrm{~A}}$ mice has suggested that leptin reduction or loss is beneficial and slows disease progression [10], while other studies have investigated the potential therapeutic impact of HFD consumption, which induces obesity and increases leptin levels, in mutant SOD1 mice [18-21] and report beneficial effects in terms of survival and improved motor behavior. Therefore, the information to date is insufficient to clarify the role of leptin in ALS or the possible pathways that link this adipokine to the pathogenesis of this disease. A greater understanding of leptin signaling in ALS is needed to determine whether leptin pathways are causally connected to ALS pathogenesis.

In this context, we examined leptin-related pathways during different ALS stages (onset and end-stage of disease) in TDP-43 ${ }^{\mathrm{A} 315 \mathrm{~T}}$ mice [22], which recapitulate several aspects of the human disease. We examined the status of leptin signaling under the backdrop of pathological CNS TDP-43 levels providing, to our knowledge, the first insights into the association between the pathways that link alterations in leptin signaling to the pathogenesis of ALS.

\section{Methods}

\subsection{Colony Maintenance and Mice Monitoring}

Transgenic (Tg) TDP43 ${ }^{\mathrm{A} 315 \mathrm{~T}}$ mice (strain no. 010700, Jackson Laboratory, Bar Harbor, ME, USA) and the genetic background-matched wild type (WT) littermate control mice were used in this study [22]. This mouse model of ALS expresses a mutant human TAR DNA binding protein TDP-43 cDNA harboring an N-terminal Flag tag and an A315T amino acid substitution associated with ALS mainly in the CNS [22,23]. To avoid the ambiguity associated with reported sex-related differences in mean survival time of TDP-43 ${ }^{\mathrm{A} 315 \mathrm{~T}}$ mice [22,23], only male mice were used. Animals expressing the hTDP-43 transgene were confirmed via PCR according to the distributor's protocol. The ALS-like disease was divided into two stages: onset (defined as the last day of individual peak body weight before a gradual loss occurs) and the end-stage of disease (defined as when weight is $20 \%$ 
below the initial weight on three consecutive days), at which the mice were euthanized. The end-stage is typically reached 2-4 weeks after symptom onset. Animals were group-housed under standard housing conditions with a $12 \mathrm{~h}$ light-dark cycle, and food and water ad libitum. To monitor disease onset and progression, all mice were weighed and assessed three times per week until the disease onset-stage, after which they were checked daily in the morning until the disease end-stage. All experimental procedures were approved by the Animal Ethics Committee of the National Hospital for Paraplegics (HNP) (Approval No 26/OH 2018) in accordance with the Spanish Guidelines for the Care and Use of Animals for Scientific Purposes.

\subsection{Tissue Preparation}

Animals were terminally anesthetized with sodium pentobarbitone $(140 \mathrm{mg} / \mathrm{kg})$ and transcardially perfused with room temperature $0.01 \mathrm{M}$ phosphate-buffered saline (PBS; $\mathrm{pH}$ 7.4), in the middle of the light cycle (between 11 AM and 1 PM). Blood was collected and processed as previously described [24]. Gonadal white adipose tissue (WAT), the hypothalamus, and lumbar spinal cord from each animal were processed to extract both mRNA and proteins for real-time PCR and Western blotting analysis. Samples were immediately frozen on dry ice and stored at $-80{ }^{\circ} \mathrm{C}$ for later analysis.

\subsection{RNA Isolation and RT-qPCR}

Total RNA was extracted following the instructions of the RNeasyPlus Mini Kit (Qiagen, Hilden, Germany). Absorbance at $260 \mathrm{~nm}$ was measured using a NanoDrop (ThermoFisher, Waltham, MA, USA) to determine RNA concentrations. For WAT and spinal cord samples, complementary DNA (cDNA) was synthesized from $1 \mu \mathrm{g}$ of total RNA as previously described [25]. Relative quantification of leptin (assay ID: Mm00434759_m1) and $O b-R b$ (assay ID: Mm00440181_m1) was performed using 10 ng of reverse-transcribed total RNA in TaqMan One-Step real-time PCR Master Mix (PE Applied Biosystem, Foster City, CA, USA). Each sample was run in duplicate and $\beta$-Actin (assay ID: Mm00607939_s1) was used as a control to normalize gene expression. The reactions were run on an ABI PRISM 7900 Fast Sequence Detection System instrument and software (Applied Biosystem, Foster City, CA, USA) according to the manufacturer's protocol.

Furthermore, for the hypothalamus samples, cDNA was synthesized from $1 \mu \mathrm{g}$ of total RNA by using the NZY First-Strand cDNA Synthesis Kit (NZYTech, Lisbon, Portugal). Quantitative real-time PCR was performed by using assay-on-demand kits (Applied Biosystems). NZY qPCR Probe Master Mix (NZYTech, Lisbon, Portugal) was used for the PCR reaction according to the manufacturer's protocol in a QuantStudio3 Detection System (Applied Biosystems, Foster City, CA, USA). Each sample was run in duplicate and glyceraldehyde 3-phosphate dehydrogenase (GAPDH; assay ID: 4352339E) was used as a control to normalize gene expression. The primers and probes used were $O b-R b$ (assay ID: Mm00440181_m1), pro-opiomelanocortin (POMC; assay ID: Mm00435874_m1), Agouti-related protein (Agrp; assay ID: Mm00475829_g1), and neuropeptide Y (NPY; assay ID: Mm03048253_m1). In all cases, relative quantification for each gene was performed by the $\Delta \Delta \mathrm{Ct}$ method [26].

\subsection{Protein Extraction and Western Blot Analysis}

Proteins were extracted from spinal cord tissue using RIPA buffer (Sigma-Aldrich, Saint Louis, MO, USA) containing a cocktail of protease inhibitors (Roche, Basel, Switzerland). For the hypothalamic samples, the supernatant collected in the RNA extraction was diluted in acetone and frozen. Afterwards, samples were centrifuged, and proteins from the hypothalamus were re-suspended in $100 \mu \mathrm{L}$ of CHAPS buffer (7M urea, 2M thiourea, $4 \%$ CHAPS, and $0.5 \%$ Tris- $\mathrm{HCl} 1 \mathrm{M}, \mathrm{pH} 8.8)$. In all cases, protein concentration was measured using the BioRad protein assay based on the Bradford method. Samples were measured at $595 \mathrm{~nm}$ on an automatic microplate analyzer (Tecan Infinite M200, Grödig, Austria). Denatured proteins (30 $\mu \mathrm{g}$ for spinal cord and $20 \mu \mathrm{g}$ for hypothalamus samples, 
respectively) were resolved using $8 \%, 10 \%$, or $12 \%$ SDS-PAGE (depending on the molecular weight of the protein assayed) and transferred onto PVDF membranes. Membranes were blocked with TBS with $0.1 \%$ Tween 20 , and $5 \%$ BSA or non-fat dried milk and incubated overnight at $4{ }^{\circ} \mathrm{C}$ with the primary antibody in blocking buffer. The primary antibodies used for the spinal cord samples were: rabbit anti-Ob-Rb (1:500; Abcam, Cambridge, UK), rabbit anti-Akt (1:1000; Cell Signaling, Danvers, MA, USA), rabbit anti-Akt (Ser473) (1:1000; Cell Signaling, Danvers, MA, USA), rabbit anti-STAT3 (1:500; Santa Cruz), and rabbit antiSTAT3 (Tyr705) (1:1000; Cell Signaling, Danvers, MA, USA). The primary antibodies used for the hypothalamic samples were: rabbit anti-LepR: (1:250, Santa Cruz, Dallas, TX, USA); mouse phospho-Akt Ser473 (1:500; Cell Signaling, Danvers, MA, USA), rabbit anti-Akt (1:1000 Santa Cruz, Dallas, TX, USA); mouse anti-STAT3 (1:1000; Cell Signaling, Danvers, MA, USA), and rabbit anti-phospho STAT3 (Tyr705) (1:500; Cell Signaling, Danvers, MA, USA); and rabbit anti-suppressor of cytokine signaling 3 (SOCS3) (1:1000; Proteintech, Rosemont, IL). A corresponding anti-rabbit or anti-mouse horseradish peroxidase (HRP)conjugated secondary antibody at a dilution of 1:7000 (Dako) or 1:2000 (Pierce, Rockford, IL, USA) for spinal cord and hypothalamus samples, respectively, were used. Mouse anti-GAPDH (1:5000, Millipore, Burlington, MA, USA) and/or mouse anti-actin (1:1000; ThermoFisher, Waltham, MA, USA) were used as the loading controls. Peroxidase activity was visualized by using Immune-Clarity Western Chemioluminiscent substrate (BioRad, Hercules, CA, USA) and determined by densitometry using an ImageQuant LAS $4000 \mathrm{mini}$ system (GE Healthcare, Little Chalfont, United Kingdom). Band intensity was measured as the integrated intensity using ImageJ software $(\mathrm{v} 1.4 ; \mathrm{NIH})$. All data were normalized to control values on each membrane.

\subsection{Measurement of Metabolic Markers in Plasma}

Total ghrelin, the adipokines resistin and leptin, and metabolic biomarkers of insulin resistance (GIP, GLP-1, glucagon, PAI-1, and insulin) from plasma samples were analyzed in duplicate by using the Bio-PlexPro mouse Diabetes group from Bio-Rad (Ref. 171F7001M, Hercules, CA, USA) and Luminex ${ }^{\circledR} 200^{\mathrm{TM}}$ technology as previously described [27]. Samples were processed following the manufacturer's instructions. According to Bio-Rad's information, the intra- and inter-assay CV variability is $<20 \%$. The final concentration value of each metabolic marker was the result of the mean from the duplicate measures.

\subsection{Statistical Analysis}

All data are presented as the mean \pm standard error of the mean (SEM). Differences between means were assessed by two-way ANOVA followed by Dunnett's post hoc test, to compare all groups with control WT onset mice, and Tukey's post hoc test was used for multiple comparisons between all groups. For multiplex assays, the mean of each experimental group was determined for all the analytes, and the Kruskal-Wallis test was performed followed by Dunnett's post hoc test to compare all groups with onset stage, while Bonferroni post hoc test was used for multiple comparisons between all groups. For all statistical tests, a $p$-value of $<0.05$ (CI 95\%) was assumed to be significant. Statistical analysis was performed using GraphPad Prism software (version 8.3.1).

\section{Results}

\subsection{Leptin Levels Are Altered in WAT of TDP-43 ${ }^{A 315 T}$ Mice}

Experimental data are limited regarding the status of leptin during the progression of ALS, even though this hormone is historically known for its important role in regulating body weight, and mild obesity appears to improve survival in ALS patients [28]. Thus, to determine the leptin expression profile in WAT, the primary source of leptin production, we first examined the levels of leptin mRNA in different phases of the disease in TDP-43 ${ }^{\mathrm{A} 315 \mathrm{~T}}$ mice compared to age-matched WT littermates (Figure 1). RT-qPCR analysis demonstrated marked differences in the expression profile of the leptin transcript during the clinical course of the disease in TDP- $43^{\mathrm{A} 315 \mathrm{~T}}$ mice compared with WT samples. There was a significant 
effect of genotype $(p=0.001)$ and disease progression $(p=0.002)$ in the expression profile of leptin mRNA in WAT (Figure 1). Indeed, although we [24] and others [23,29-31] have previously reported that TDP- $43^{\mathrm{A} 315 \mathrm{~T}}$ mice exhibit weight loss during disease progression, Tukey's post hoc test demonstrated a statistically significant up-regulation of leptin mRNA levels in WAT at the onset stage in TDP- $43^{\mathrm{A} 315 \mathrm{~T}}$ mice, followed by a significant increase in its mRNA expression at the end-stage of disease compared to age-matched WT littermates $(p=0.02$ and $p=0.03$, respectively; Figure 1$)$.

\section{WAT}

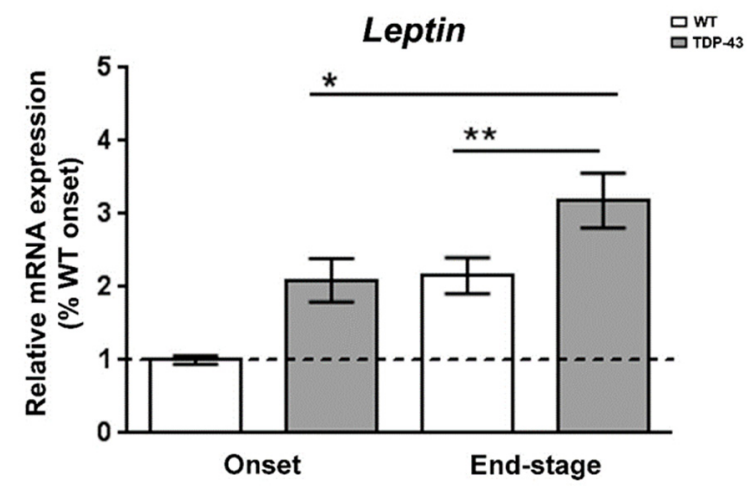

Figure 1. Alterations in leptin expression in the WAT in TDP-43 ${ }^{\mathrm{A} 315 \mathrm{~T}}$ mice. Leptin mRNA expression was assessed by RT-qPCR in TDP-43 ${ }^{\mathrm{A} 315 \mathrm{~T}}$ mice compared to age-matched WT littermates at both onset and end-stage of disease. Values are expressed as the mean \pm SEM for the different groups ( $n=5$ per genotype/stage of disease). Comparison between groups was performed by two-way ANOVA followed by Dunnett's post hoc test to compare all groups with WT onset stage, while Tukey's post hoc test was used for multiple comparisons between all groups, where $p<0.05$ vs. WT onset stage; $^{* *} p<0.05$ vs. WT end-staged. Abbreviations: WAT, white adipose tissue.

\subsection{Peripheral Levels of Leptin, Ghrelin, and Resistin Are Altered in Plasma of TDP-43 ${ }^{A 315 T}$ Mice}

Circulating leptin levels were reduced in both ALS stages in TDP-43 ${ }^{\mathrm{A} 315 \mathrm{~T}}$ mice compared to age-matched controls, being significantly lower at disease termination in the affected mice $\left(\mathrm{F}_{(3,12)}=3.875, p=0.03\right.$; Figure $\left.2 \mathrm{~A}\right)$. Ghrelin and resistin levels also showed differences between the ALS stages, as well as genotype-specific differences (Figure 2B,C). Dunnett's post hoc test demonstrated a significant increase in total ghrelin concentrations in both WT and TDP-43 ${ }^{\mathrm{A} 315 \mathrm{~T}}$ mice at the end-stage of disease compared to the onset stage ( $p=0.01$ and $p=0.007$, respectively; Figure 2B). Circulating resistin concentrations were lower in TDP-43 ${ }^{\mathrm{A} 315 \mathrm{~T}}$ mice compared to age-matched WT littermates, with this reaching statistical significance at the end-stage of disease $(p=0.001$; Figure 2C).

To further analyze metabolism, circulating levels of PAI-1, GIP, GLP-1, insulin, and glucagon peptides were measured in TDP- $43^{\mathrm{A} 315 \mathrm{~T}}$ and age-matched WT littermates at both time-points of the disease. No statistically significant differences were found between TDP- $43^{\mathrm{A} 315 \mathrm{~T}}$ and WT mice at either of the time-points analyzed (Figure $2 \mathrm{~F}-\mathrm{H}$ ); however, Dunnett's post hoc test demonstrated a significant increase in PAI-1 peptide concentrations in TDP-43 $3^{\mathrm{A} 315 \mathrm{~T}}$ mice at the end-stage of the disease compared to circulating PAI- 1 levels in WT mice at the onset stage ( $p=0.02$; Figure 2D). Indeed, no linear correlation was found using Spearman's test among the plasma levels of these metabolic proteins in WT controls or TDP- $43^{\mathrm{A} 315 \mathrm{~T}}$ mice throughout the clinical course of the disease (data not shown). 
A

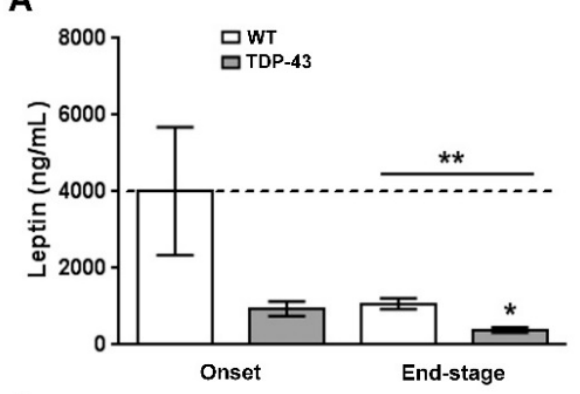

\section{C}

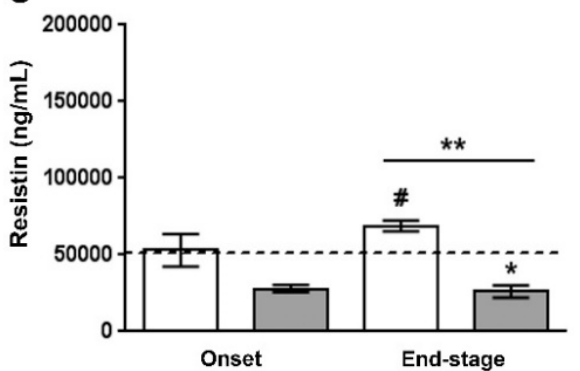

E

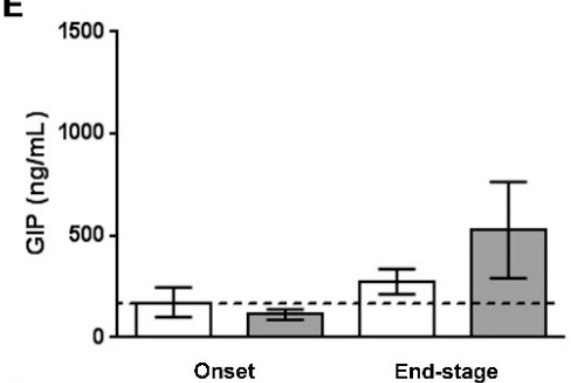

G

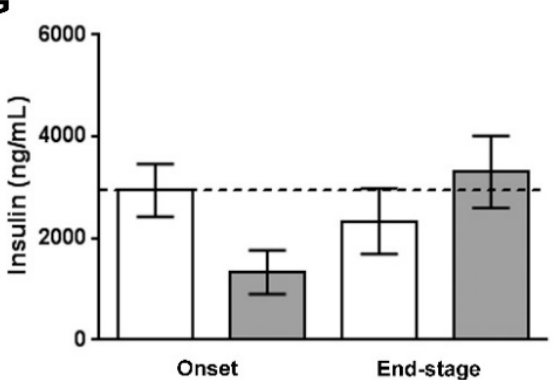

B

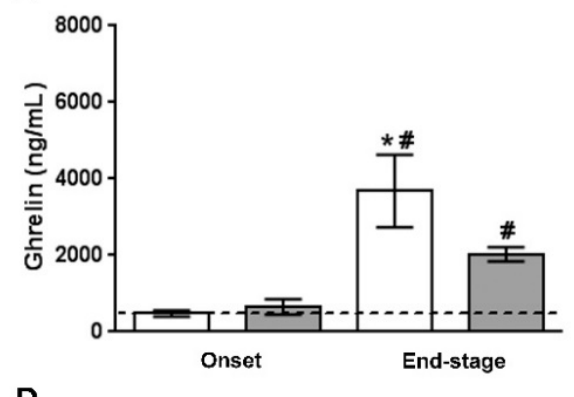

D

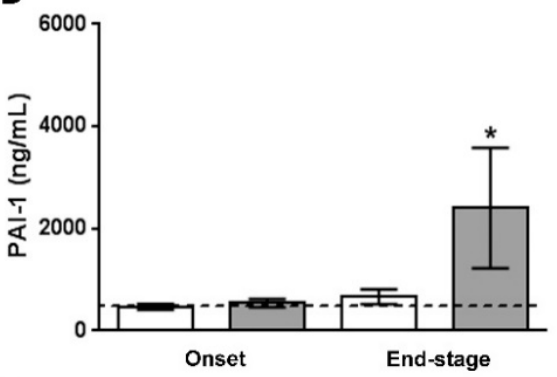

$\mathbf{F}$

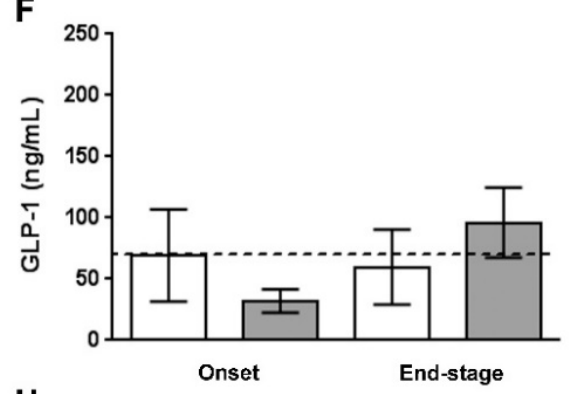

H

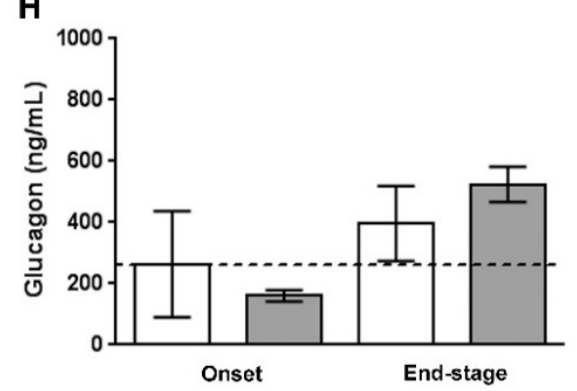

Figure 2. Adipocytokines and metabolic biomarkers levels in WT controls and TDP-43A315T mice. Total plasma leptin (A), ghrelin (B) and the adipokine resistin (C), and (D-H) metabolic biomarkers of insulin resistance (PAI-1, GIP, GLP-1, insulin, and glucagon) were measured over the time course of the disease in TDP-43 ${ }^{\mathrm{A} 315 \mathrm{~T}}$ mice compared to age-matched WT littermates using Luminex ${ }^{\circledR}$ $200^{\mathrm{TM}}$ technology. Values are expressed as the mean \pm SEM for the different groups $(\mathrm{n}=5$ per genotype/stage of disease). Kruskal-Wallis test was performed followed by Dunnett's post hoc test to compare all groups with WT onset stage, while Bonferroni post hoc test was used for multiple comparisons between all groups, where * $p<0.05$ vs. WT onset stage; ${ }^{*} p<0.05$ vs. TDP- $43^{A 315 T}$ onset; ** $p<0.05$ vs. WT end-staged. Abbreviations: PAI-1, plasminogen activator inhibitor type 1; GIP, gastric inhibitory peptide; GLP-1, glucagon like peptide 1.

\subsection{Hypothalamic Leptin Signaling in TDP-43 ${ }^{A 315 T}$ Mice}

We next studied how leptin signaling and leptin-sensitive genes involved in metabolism were affected in the hypothalamus of TDP- $43^{\mathrm{A} 315 \mathrm{~T}}$ mice over the time course of the disease. RT-qPCR analysis demonstrated a significant effect of genotype $(p=0.001)$ and disease progression $(p=0.002)$ on the expression profile of $O b-R b$ mRNA in the hypothalamus (Figure 3A). Dunnett's post hoc test showed that $O b-R b$ mRNA levels were upregulated 
in the hypothalamus of TDP- $43^{\mathrm{A} 315 \mathrm{~T}}$ mice at both time points of the disease compared to age-matched WT controls ( $p=0.03$ and $p=0.001$, respectively; Figure $3 \mathrm{~A}$ ). In addition, as central hypothalamic leptin signaling has a critical role in promoting energy homeostasis via modulation of food intake and energy expenditure [32], we also investigated the mRNA levels of $P O M C, A g R P$, and NPY neuropeptides (Figure 3B-D), that play essential roles in the regulation of food intake and energy homeostasis in mammals. RT-qPCR analysis demonstrated differences in the pattern of expression of POMC, NPY, and AgRP genes between TDP-43 ${ }^{\mathrm{A} 315 \mathrm{~T}}$ and WT mice at both disease stages. There were significant effects of genotype $(p=0.03)$ and disease progression $(p=0.0007)$ in the expression profile of $P O M C$ mRNA in the hypothalamus (Figure 3B), with an overall increase in POMC mRNA with age in both genotypes. In TDP-43 ${ }^{\mathrm{A} 315 \mathrm{~T}}$ mice POMC mRNA levels were lower than in WT at both onset and end-stage, with this increase being significant at the end-stage of disease compared to POMC mRNA levels in WT controls at the onset ( $p=0.04$; Figure 3B). In addition, RT-qPCR analysis demonstrated a significant effect of genotype ( $p=0.0009$ and $p=0.0005$, respectively) and disease progression $(p=0.0004$ and $p=0.002$, respectively; Figure $3 \mathrm{C}, \mathrm{D})$ on the expression profile of $N P Y$ and $A g R P$ mRNA levels in the hypothalamus. Although Dunnett's post hoc test demonstrated no age-dependent changes in NPY and $A g R P$ mRNA levels in TDP-43 ${ }^{\mathrm{A} 315 \mathrm{~T}}$ mice compared to WT mice at the onset stage, Tukey's post hoc test demonstrated a statistically significant hypothalamic upregulation of both orexigenic neuropeptides (NPY: $p=0.002$, Figure 3C; and $A g R P: p=0.0007$, Figure 3D) at the end-stage of disease in the hypothalamus of TDP- $43^{\mathrm{A} 315 \mathrm{~T}}$ mice relative to age-matched WT controls.

A

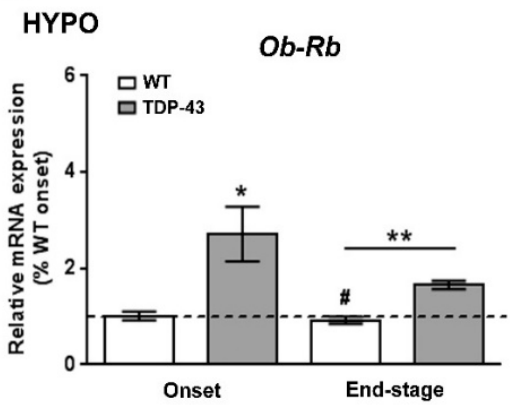

C

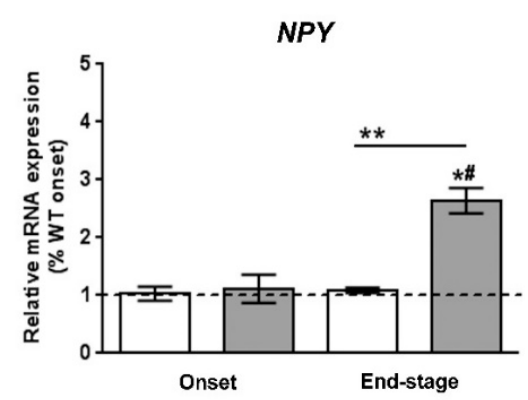

B

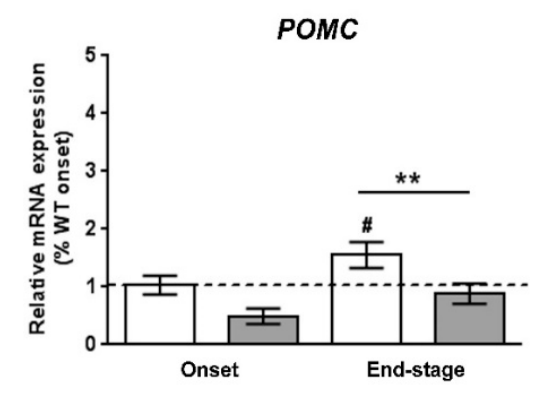

$\mathbf{D}$

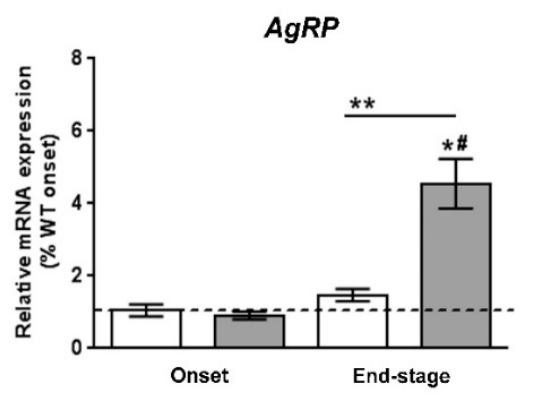

Figure 3. Alterations in $O b-R b$ and anorexigenic and orexigenic neuropeptides in the hypothalamus of TDP-43 ${ }^{\mathrm{A} 315 \mathrm{~T}}$ mice. (A) Ob-Rb mRNA expression, (B) POMC, (C) NPY, and (D) AgRP transcripts were assessed by RT-qPCR in TDP-43 ${ }^{\mathrm{A} 315 \mathrm{~T}}$ mice compared to age-matched WT littermates at both onset and end-stage of disease. Values are expressed as the mean \pm SEM for the different groups ( $n=5$ per genotype/stage of disease). Comparison between groups was performed by two-way ANOVA followed by Dunnett's post hoc test to compare all groups with WT onset stage, while Tukey's post hoc test was used for multiple comparisons between all groups, where ${ }^{*} p<0.05$ vs. WT onset stage; ${ }^{\#} p<0.05$ vs. TDP-43 ${ }^{\mathrm{A} 315 \mathrm{~T}}$ onset; ${ }^{* *} p<0.05$ vs. WT end-staged. Abbreviations: $\mathrm{HYPO}$, hypothalamus; Ob-Rb, long form of leptin receptor; POMC, Proopiomelanocortin; Agrp, Agouti-related protein; NPY, neuropeptide Y. 
We next investigated the protein levels of Ob-Rb (Figure 4A) and SOCS3 (Figure 4B), the main inhibitor of leptin signaling in the brain, as well as the status of the STAT3 $\left(\mathrm{pTyr}^{705}\right.$ STAT3) and Akt (pSer ${ }^{473}$-Akt) pathways, which are downstream of the Ob-Rb receptor (Figure $4 \mathrm{C}, \mathrm{D}$ ). Immunoblotting analysis demonstrated that $\mathrm{Ob}-\mathrm{Rb}$ was also altered at the protein level in TDP-43 ${ }^{\mathrm{A} 315 \mathrm{~T}}$ mice (Figure 4A). There was a significant effect of disease progression $(p=0.005)$ on the expression profile of the $\mathrm{Ob}-\mathrm{Rb}$ receptor in the hypothalamus. In contrast to mRNA levels, protein levels of the $\mathrm{Ob}-\mathrm{Rb}$ receptor were lower in TDP-43 ${ }^{\mathrm{A} 315 \mathrm{~T}}$ mice compared to age-matched WT controls, which reached significance $(p=0.01)$ at the end-stage of disease (Figure $4 \mathrm{~A}$ ). In addition, we found no significant effect of either disease stage or genotype on SOCS3 levels (Figure 4B). There was a significant effect of genotype $(p=0.0001)$ on the phosphorylation levels of Akt protein in the hypothalamus (Figure $4 \mathrm{C}$ ). At the end-stage of the disease, Akt phosphorylation levels were significantly decreased in the hypothalamus of both genotypes ( $p=0.001$ and $p<0.0001$, respectively) compared to WT controls as well as compared to TDP-43 ${ }^{\mathrm{A} 315 \mathrm{~T}}$ mice ( $p=0.01$ and $p=0.0008$, respectively) at the onset stage (Figure $4 \mathrm{C}$ ). In addition, there was no effect of genotype or disease progression on the phosphorylation levels of STAT3 protein in the hypothalamus (Figure 4D).

A
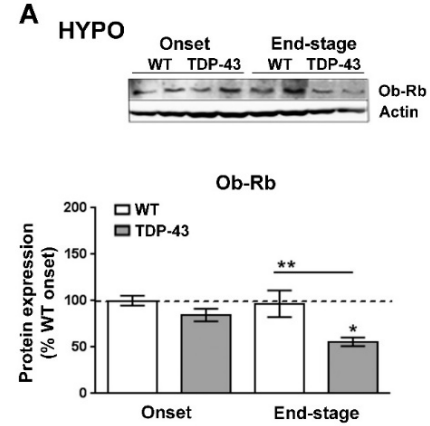

C

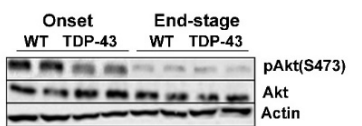

pAkt(S473)/Akt

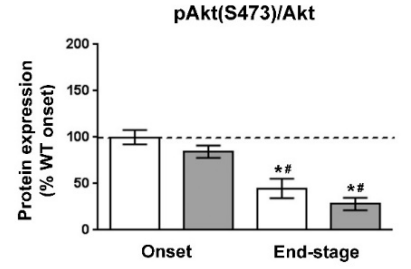

B
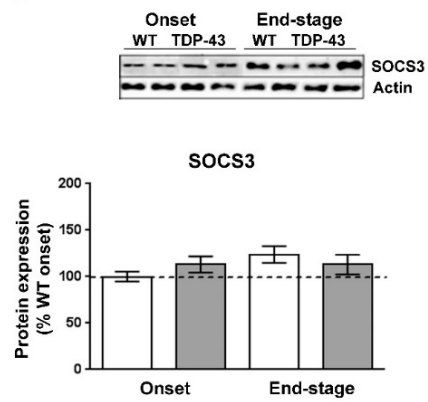

D \begin{tabular}{lll}
$\begin{array}{c}\text { Onset } \\
\text { WT }\end{array}$ TDP-43 & $\begin{array}{c}\text { End-stage } \\
\text { WT TDP-43 }\end{array}$ \\
\hline
\end{tabular} pSTAT3(Tyr705) - STAT3

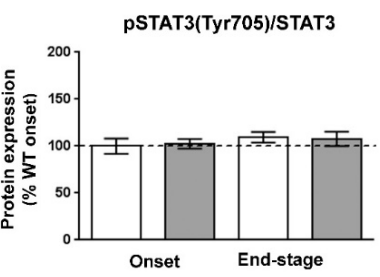

Figure 4. Alterations in serine phosphorylation of Akt in the hypothalamus of TDP- $43^{\mathrm{A} 315 \mathrm{~T}}$ mice. Representative actin-normalized immunoblot images and quantitation of (A) Ob-Rb receptor, (B) SOCS3, (C) pAkt (pSer ${ }^{473}$-Akt) protein, (D) pSTAT3 (pTyr705-STAT3) proteins, respectively, in hypothalamic extracts of TDP-4 $3^{\mathrm{A} 315 \mathrm{~T}}$ mice compared to age-matched WT littermates at both onset and end-stage of disease. Values are expressed as the mean \pm SEM for the different groups $(n=5$ per genotype/stage of disease). Comparison between groups was performed by two-way ANOVA followed by Dunnett's post hoc test to compare all groups with WT onset stage, while Tukey's post hoc test was used for multiple comparisons between all groups, where ${ }^{*} p<0.05$ vs. WT onset stage; ${ }^{\#} p<0.05$ vs. TDP- $43^{\mathrm{A} 315 \mathrm{~T}}$ onset; ${ }^{* *} p<0.05$ vs. WT end-staged. In the immunoblot images, representative bands were run on the same gel but were non-contiguous. Abbreviations: $\mathrm{HYPO}$, hypothalamus; $\mathrm{Ob}-\mathrm{Rb}$, long form of leptin receptor; SOCS3, suppressor of cytokine signaling 3; Akt, serine/threonine kinase; STAT3, signal transducer and activator of transcription 3. 


\subsection{Leptin Signaling in the Spinal Cord of TDP-43 ${ }^{A 315 T}$}

Since leptin signaling has actions throughout the CNS [33], and the results of our study could possibly indicate that the reduction in circulating leptin levels is associated with altered hypothalamic leptin signaling in TDP- $43^{\mathrm{A} 315 \mathrm{~T}}$ mice, particularly at the end-stage of the disease, we analyzed if leptin signaling in the spinal cord tissue of TDP- $43^{\mathrm{A} 315 \mathrm{~T}}$ mice differed from that of WT mice. Although there was no effect of genotype, RT-qPCR analysis demonstrated that there was a significant effect of disease progression $(p=0.01)$ on the expression profile of $\mathrm{Ob}-\mathrm{Rb}$ receptor in the spinal cord (Figure 5A). In addition, Tukey's post hoc test demonstrated a statistically significant down-regulation of $O b-R b$ mRNA at the end-stage of the disease in the spinal cord of TDP-43 ${ }^{\mathrm{A} 315 \mathrm{~T}}$ mice relative to age-matched WT littermates ( $p=0.02$, Figure $5 \mathrm{~A})$. In contrast, $\mathrm{Ob}-\mathrm{Rb}$ protein levels were increased in the spinal cord of TDP- $43^{\mathrm{A} 315 \mathrm{~T}}$ mice compared to WT at both onset and end-stage of the disease ( $p=0.001$ and $p=0.04$, respectively; Figure $5 \mathrm{~B}$ ). In addition, there was a significant effect of genotype $(p=0.005)$ and disease progression $(p=0.0006)$ on the phosphorylation levels of Akt protein in the spinal cord (Figure 5C). Dunnett's post hoc test showed that phosphorylation levels of Akt protein was significantly upregulated in the spinal cord of WT mice and TDP-43 ${ }^{\mathrm{A} 315 \mathrm{~T}}$ mice at both time-points of the disease compared to WT controls $(p<0.0001, p=0.002$ and $p<0.0001$, respectively) at the onset stage (Figure 5C). Finally, there was a significant effect of genotype ( $p=0.0001$; Figure 5D) on the phosphorylation levels of STAT3 protein in the spinal cord, with levels increasing in both genotypes with age. Indeed, Dunnett's post hoc test demonstrated that phosphorylation levels of STAT3 protein were significantly decreased at the end-stage of the disease in TDP- $43^{\mathrm{A} 315 \mathrm{~T}}$ compared to WT controls at the onset stage ( $p=0.004$; Figure 5D).

A

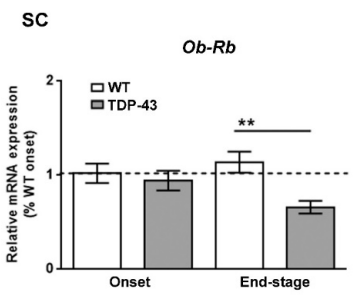

C
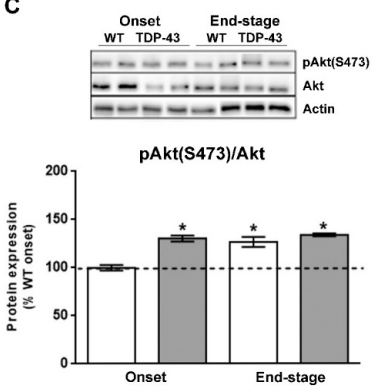

B

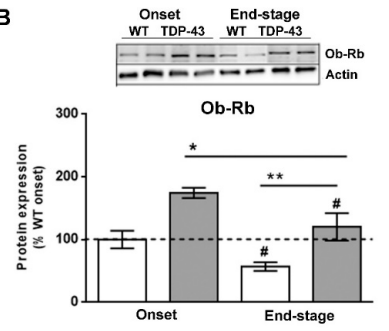

D

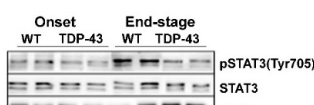

STAT3

pSTAT3(Tyr705)/STAT3

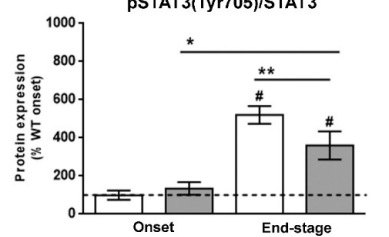

Figure 5. Alterations in tyrosine phosphorylation of STAT3 in the spinal cord of TDP-43 ${ }^{\mathrm{A} 315 \mathrm{~T}}$ mice. (A) mRNA expression of $O b-R b$ receptor was assessed by RT-qPCR in TDP-43 ${ }^{\mathrm{A} 315 \mathrm{~T}}$ mice compared to age-matched WT littermates at both onset and end-stage of disease. Representative GAPDHnormalized immunoblot images and quantitation of (B) Ob-Rb receptor, (C) pAkt (pSer ${ }^{473}$-Akt) protein, (D) pSTAT3 (pTyr705-STAT3) protein in spinal extracts of TDP-43 ${ }^{\mathrm{A} 315 \mathrm{~T}}$ mice compared to age-matched WT littermates at the onset and end-stage of disease. Values are expressed as the mean \pm SEM for the different groups ( $n=5$ per genotype/stage of disease). Comparison between groups was performed by two-way ANOVA followed by Dunnett's post hoc test to compare all groups with WT onset stage, while Tukey's post hoc test was used for multiple comparisons between all groups, where ${ }^{*} p<0.05$ vs. WT onset stage; ${ }^{\#} p<0.05$ vs. TDP-43 ${ }^{\mathrm{A} 315 \mathrm{~T}}$ onset; ${ }^{* *} p<0.05$ vs. WT end-staged. In the immunoblot images, representative bands were run on the same gel but were non-contiguous. Abbreviations: SC, spinal cord; Ob-Rb, long form of leptin receptor; SOCS3, Suppressor of cytokine signaling 3; Akt, serine/threonine kinase; STAT3, signal transducer and activator of transcription 3. 


\section{Discussion}

A growing body of evidence indicates disturbances in energy metabolism in ALS [34-37], suggesting that targeting metabolism could represent a rational strategy to treat this disease. Metabolic abnormalities have been reported in both ALS patients [19] and mouse models of ALS [10], as well as in the more recently developed murine model of ALS/FTD, TDP-43 proteinopathy $[38,39]$. Two epidemiological studies provided the first evidence of leptin as a potential novel therapeutic target in ALS [12,40], although very little is known about the direct influence of leptin in altering energy metabolism and disease progression in ALS, as it has thus far been correlated with the protection exerted by increased fat mass stores. Indeed, even though leptin signaling appears to be involved in ALS, our understanding of its biological role in mechanisms of disease pathogenesis is limited. Here, we present evidence of alterations in leptin signaling in the peripheral and CNS of the TDP43 ${ }^{\mathrm{A} 315 \mathrm{~T}}$ transgenic ALS mouse model, providing novel insights about the pathways that could link alterations in leptin to ALS disease.

The majority of circulating leptin is produced in adipose tissue [41], with leptin mRNA levels normally being directly correlated with adipocyte size, and high circulating levels of this hormone are associated with obesity [41,42]. The opposite is observed in ALS patients [43,44] as ALS causes loss of body weight, reduced fat mass, and reduced circulating leptin levels. Here, we report an up-regulation of leptin mRNA levels in WAT of TDP- $43^{\mathrm{A} 315 \mathrm{~T}}$ mice, both at onset and at the end-stage of the disease. This observation is of interest because peripheral leptin levels are positively correlated with adipose tissue mass in TDP- $43^{\mathrm{A} 315 \mathrm{~T}}$ mice, as we previously reported a progressive decline in body weight in TDP-43 ${ }^{\mathrm{A} 315 \mathrm{~T}}$ mice compared to WT controls [24], which is in agreement with reduced circulating levels of this adipokine. Indeed, circulating plasma levels of leptin were lower in TDP-43 ${ }^{\mathrm{A} 315 \mathrm{~T}}$ mice compared to WT mice at both ALS stages, which is in accordance with the decrease in body weight [23,29-31]. Nevertheless, although the reduction in circulating levels of leptin is in accordance with a lower adipose tissue mass, the mRNA levels of leptin/ $\mu$ g adipose tissue are upregulated in TDP- $43^{\mathrm{A} 315 \mathrm{~T}}$ mice suggesting an attempt to maintain normal circulating levels of this adipokine. This observation is of interest because the evidence supports that cachexia may occur in the early course of ALS [45], even before the loss of motor neurons and neurodegeneration begin [46]. Indeed, WAT is specialized in the storage of triglycerides (TGs) [47] and patients with ALS suffer from hypolipidemia [36]. In this context, as adipose tissue wasting has been shown to occur before the appearance of classical cachexia markers, as for example loss of fat mass, and subsequently, loss of body weight, it will be interesting in future in vitro studies to determine the mechanism of leptin regulation in primary adipocytes of mutant TDP-43. Considering that cachexia may occur in the early stages of ALS, our results might suggest that leptin is a potential biomarker of adipose tissue wasting, and subsequently, the muscle atrophy and depletion of fat stores clinical features in ALS.

In addition to the marked decrease in circulating leptin concentrations, our results confirm disease stage-dependent alterations in the circulating levels of ghrelin and resistin in TDP-43 ${ }^{\mathrm{A} 315 \mathrm{~T}}$ mice. Plasma levels of ghrelin, an appetite-stimulating hormone, were highest in WT animals at the end-stage of the disease and although there was an increase between onset and end-stage in TDP-43 ${ }^{\mathrm{A} 315 \mathrm{~T}}$ mice they remained significantly lower compared to WT, which could partly be due to modifications in food intake and ultimately the loss of body weight in TDP-43 ${ }^{\mathrm{A} 315 \mathrm{~T}}$ mice [23,29-31]. Indeed, low plasma ghrelin levels have been found in ALS patients [11]. We also found lower circulating levels of the adipokine resistin in TDP- $43^{\mathrm{A} 315 \mathrm{~T}}$ mice both at the onset and end-stage of ALS disease. This result supports previous data from our group showing downregulation of peripheral protein resistin levels in TDP-43 ${ }^{\mathrm{A} 315 \mathrm{~T}}$ mice [24]. However, although no difference in plasma levels of resistin was found between controls and ALS patients [11], this data might indicate that resistin levels are directly associated with metabolic abnormalities in TDP-43 ${ }^{\mathrm{A} 315 \mathrm{~T}}$ mice. However, future experiments should try to corroborate this hypothesis. 
We examined leptin signaling in the hypothalamus and spinal cord of TDP-43 ${ }^{\mathrm{A} 315 \mathrm{~T}}$ mice, as they represent two areas of the nervous system vulnerable to ALS, where leptin could play an important role. In both tissues, there was an up-regulation in the expression levels of $O b-R b$ transcript in TDP-43 ${ }^{\mathrm{A} 315 \mathrm{~T}}$ mice compared to age-matched WT littermates. The observation in spinal cord is of particular interest as a previous study conducted in rats showed a significant upregulation of $O b-R b$ mRNA after spinal cord injury [5] and thus, our result may reflect the progressive irreversible neurodegenerative damage that characterizes ALS pathogenesis. Alternative splicing of the $O b R$ gene generates distinct isoforms of the leptin receptor, including long $(\mathrm{Ob}-\mathrm{Rb})$ and short isoforms (Ob-Ra and $\mathrm{Ob}-\mathrm{Rc}-\mathrm{f})$ that differ in the length of their intracellular cytoplasmic domains, a region that contains specific motifs involved in leptin signaling [48,49]. In this context, the increase in $O b-R b$ mRNA expression, but decrease in protein levels, could indicate an increase in $\mathrm{Ob}-\mathrm{Rb}$ receptor turnover or a modification in processing, producing less long-form and more of the other forms. However, future experiments are necessary to corroborate this hypothesis. Alternatively, although the precise dynamics of $\mathrm{Ob}-\mathrm{Rb}$ regulation in these areas of the nervous system are not completely understood, TDP-43 pathology and consequently the progression of ALS stages may be related to disruption of leptin signaling. Of particular interest are the Akt and STAT3 pathways downstream of the $\mathrm{Ob}-\mathrm{Rb}$ receptor, as they are important targets in the regulation of glucose and energy metabolism [50]. Indeed, we have previously reported that TDP-43 ${ }^{\mathrm{A} 315 \mathrm{~T}}$ mice are hypoglycemic compared to WT mice at the disease end-stage, confirming the disturbances in the energy metabolism of the TDP-43 ${ }^{\mathrm{A} 315 \mathrm{~T}}$ mouse model reported previously [51]. Here, a significant decrease in serine phosphorylation of Akt was found in the hypothalamus of TDP-43 ${ }^{\mathrm{A} 315 \mathrm{~T}}$ mice at the end-stage, while no differences were founded between genotypes in spinal cord tissue over the time course of the disease, which could represent the different physiological roles that leptin exerts in these two brain areas. In addition, while no differences in tyrosine phosphorylation of STAT3 were observed in the hypothalamus over the time course of the disease, increased phosphorylation of STAT3 was observed in the spinal cord of TDP-43 ${ }^{\mathrm{A} 315 \mathrm{~T}}$ and WT mice at the end-stage of the disease compared to the onset stage, in accordance with previous research conducted in $\mathrm{SOD} 1^{\mathrm{G} 93 \mathrm{~A}}$ mice $[52,53]$.

It is conceivable that changes in leptin signaling in the spinal cord of TDP-43 ${ }^{\mathrm{A} 315 \mathrm{~T}}$ mice could potentially be due to a direct effect of leptin on motor neurons. Indeed, we are currently evaluating the presence of $\mathrm{Ob}-\mathrm{Rb}$ protein in TDP-43 ${ }^{\mathrm{A} 315 \mathrm{~T}}$ mice, and our preliminary unpublished data indicate the presence of the $\mathrm{Ob}-\mathrm{Rb}$ receptor in a minority of cells in the ventral horn of the spinal cord tissue of TDP-43 ${ }^{\mathrm{A} 315 \mathrm{~T}}$ and WT mice that have morphological characteristics of motor neurons. However, further studies investigating $\mathrm{Ob}-\mathrm{Rb}$ localization within the spinal cord between genotypes may be warranted.

Leptin is reported to activate POMC neurons and inhibit AgRP/NPY neurons, at least in part through the STAT3 pathway [50]. Indeed, the regulation of glucose homeostasis is related to leptin signaling in the hypothalamic POMC and NPY/AgRP neurons. Neuropeptides derived from POMC provide a strong anorexigenic effect (i.e., decreases food intake), while NPY / AgRP neurons have a potent orexigenic effect (i.e., increase food intake). Thus, in a situation of negative energy balance, such as the malnutrition observed in ALS, the expression of NPY and AgRP is normally increased and POMC expression decreased [54,55]. Consistently, our data showed an up-regulation of NPY and AgRP in TDP-43 ${ }^{\mathrm{A} 315 \mathrm{~T}}$ mice at disease end-stage, as previously reported by others in ALS patients and several animal models [56,57], and an overall decrease in POMC expression. These alterations in metabolic neuropeptides could partly explain the hypoglycemic state observed in TDP-43 ${ }^{\mathrm{A} 315 \mathrm{~T}}$ mice [24]. However, collectively, these transcriptional modifications at the end-stage of disease in TDP-43 ${ }^{\mathrm{A} 315 \mathrm{~T}}$ mice might reflect the physiological response of the hypothalamus to overcome adipose atrophy and loss of body weight.

One caveat of this study that should be taken into consideration is that only the mRNA levels of hypothalamic neuropeptides and of leptin in WAT were measured, which may or may not reflect the changes occurring in protein production. Tissue levels of a 
secreted protein, such as, for example, leptin in adipose tissue, most likely do not reflect modifications in its production as these proteins can be continuously secreted. The inverse may also occur, such as in neuropeptides where an increase in cellular levels may actually reflect reduced secretion and not increased production. Indeed, in most metabolic studies only the mRNA levels of neuropeptides are analyzed. However, it should also be taken into consideration that in ALS specific RNA-binding interference has been reported $[58,59]$ that could also alter the correlation between an mRNA and its corresponding protein levels.

\section{Conclusions}

In summary, our study provides the first experimental evidence suggesting that ALS may be associated with alterations in leptin signaling pathways that might result in a leptinresistant state, and that this could play a critical role in the irreversible and progressive characteristic pathological changes associated with this disease. However, the precise pathways that could link leptin signaling to the TDP-43 proteinopathy model of ALS remain unclear. Further mechanistic studies analyzing the consequences of leptin signaling alterations may require the inclusion of additional defined time points, as well as larger sample sizes. Determining the role of leptin and its mechanistic actions may provide a new avenue for therapeutic development for this fatal condition.

Author Contributions: Conceptualization, C.M.F.-M.; data curation, C.M.F.-M. and A.F.-D.; formal analysis, A.C., L.M.F. and C.M.F.-M.; funding acquisition, J.A.C. and C.M.F.-M.; investigation, A.C., L.M.F. and C.M.F.-M.; methodology, A.F.-D., A.C., L.M.F. and C.M.F.-M.; project administration, C.M.F.-M.; resources, J.A.C. and C.M.F.-M.; software, A.C. and L.M.F.; supervision: J.A.C. and C.M.F.M.; validation, A.C., L.M.F., J.A.C. and C.M.F.-M.; visualization, A.C., L.M.F., J.A.C. and C.M.F.-M.; writing-original draft, A.C. and C.M.F.-M.; writing-review and editing: A.C., L.M.F., J.A.C. and C.M.F.-M. All authors have read and agreed to the published version of the manuscript.

Funding: This work was supported by funding from the Consejería de Educación, Cultura y Deportes, Fondo Europeo de Desarrollo Regional (FEDER), Junta de Comunidades de Castilla-La Mancha (SBPLY/17/180501/000303), and the Ministry of Education, Science and Innovation, Spain (BFU201782565-C2-1-R-to LMF and JAC and CIBEROBN Instituto Carlos III (JAC).

Institutional Review Board Statement: The study was conducted according to the guidelines of the Declaration of Helsinki and approved by the Animal Ethics Committee of the National Hospital for Paraplegics (HNP) (Approval No 26/OH 2018) in accordance with the Spanish Guidelines for the Care and Use of Animals for Scientific Purposes.

Informed Consent Statement: Not applicable.

Data Availability Statement: Not applicable.

Acknowledgments: The authors would like to gratefully acknowledge Sandra Canelles and the Surgery Unit of the UDI-HNP for their excellent technical support.

Conflicts of Interest: The authors declare no conflict of interest.

\section{References}

1. Tapia, R. Cellular and molecular mechanisms of motor neuron death in amyotrophic lateral sclerosis: A perspective. Front. Cell Neurosci. 2014, 8, 241. [CrossRef]

2. Stephens, T.W.; Basinski, M.B.; Bristow, P.K.; Bue-Valleskey, J.M.; Burgett, S.G.; Craft, L.S.; Hale, E.J.; Hoffmann, J.; Hsiung, H.M.; Kriauciunas, A.; et al. The role of neuropeptide $\mathrm{Y}$ in the antiobesity action of the obese gene product. Nature 1995, 377, 530-532. [CrossRef] [PubMed]

3. Zhang, Y.; Proenca, R.; Maffei, M.; Barone, M.; Leopold, L.; Friedman, J.M. Positional cloning of the mouse obese gene and its human homologue. Nature 1994, 372, 425-432. [CrossRef] [PubMed]

4. Friedman, J.M.; Halaas, J.L. Leptin and the regulation of body weight in mammals. Nature 1998, 395, 763-770. [CrossRef] [PubMed]

5. Fernandez-Martos, C.M.; Gonzalez, P.; Rodriguez, F.J. Acute leptin treatment enhances functional recovery after spinal cord injury. PLoS ONE 2012, 7, e35594. [CrossRef] [PubMed]

6. Zhang, F.; Wang, S.; Signore, A.P.; Chen, J. Neuroprotective effects of leptin against ischemic injury induced by oxygen-glucose deprivation and transient cerebral ischemia. Stroke 2007, 38, 2329-2336. [CrossRef] 
7. Fewlass, D.C.; Noboa, K.; Pi-Sunyer, F.X.; Johnston, J.M.; Yan, S.D.; Tezapsidis, N. Obesity-related leptin regulates Alzheimer's Abeta. FASEB J. 2004, 18, 1870-1878. [CrossRef] [PubMed]

8. Greco, S.J.; Sarkar, S.; Casadesus, G.; Zhu, X.; Smith, M.A.; Ashford, J.W.; Johnston, J.M.; Tezapsidis, N. Leptin inhibits glycogen synthase kinase-3beta to prevent tau phosphorylation in neuronal cells. Neurosci. Lett. 2009, 455, 191-194. [CrossRef]

9. Greco, S.J.; Sarkar, S.; Johnston, J.M.; Tezapsidis, N. Leptin regulates tau phosphorylation and amyloid through AMPK in neuronal cells. Biochem. Biophys. Res. Commun. 2009, 380, 98-104. [CrossRef] [PubMed]

10. Lim, M.A.; Bence, K.K.; Sandesara, I.; Andreux, P.; Auwerx, J.; Ishibashi, J.; Seale, P.; Kalb, R.G. Genetically altering organismal metabolism by leptin-deficiency benefits a mouse model of amyotrophic lateral sclerosis. Hum. Mol. Genet. 2014, 23, 4995-5008. [CrossRef]

11. Ngo, S.T.; Steyn, F.J.; Huang, L.; Mantovani, S.; Pfluger, C.M.; Woodruff, T.M.; O'Sullivan, J.D.; Henderson, R.D.; McCombe, P.A. Altered expression of metabolic proteins and adipokines in patients with amyotrophic lateral sclerosis. J. Neurol. Sci. 2015, 357, 22-27. [CrossRef] [PubMed]

12. Nagel, G.; Peter, R.S.; Rosenbohm, A.; Koenig, W.; Dupuis, L.; Rothenbacher, D.; Ludolph, A.C. Adipokines, C-reactive protein and Amyotrophic Lateral Sclerosis—Results from a population- based ALS registry in Germany. Sci. Rep. 2017, 7, 4374. [CrossRef] [PubMed]

13. Ahmed, R.M.; Phan, K.; Highton-Williamson, E.; Strikwerda-Brown, C.; Caga, J.; Ramsey, E.; Zoing, M.; Devenney, E.; Kim, W.S.; Hodges, J.R.; et al. Eating peptides: Biomarkers of neurodegeneration in amyotrophic lateral sclerosis and frontotemporal dementia. Ann. Clin. Transl. Neurol. 2019, 6, 486-495. [CrossRef] [PubMed]

14. Chen-Plotkin, A.S.; Lee, V.M.; Trojanowski, J.Q. TAR DNA-binding protein 43 in neurodegenerative disease. Nat. Rev. Neurol. 2010, 6, 211-220. [CrossRef] [PubMed]

15. Morozova, N.; Weisskopf, M.G.; McCullough, M.L.; Munger, K.L.; Calle, E.E.; Thun, M.J.; Ascherio, A. Diet and amyotrophic lateral sclerosis. Epidemiology 2008, 19, 324-337. [CrossRef]

16. Okamoto, K.; Kihira, T.; Kondo, T.; Kobashi, G.; Washio, M.; Sasaki, S.; Yokoyama, T.; Miyake, Y.; Sakamoto, N.; Inaba, Y.; et al. Nutritional status and risk of amyotrophic lateral sclerosis in Japan. Amyotroph. Lateral Scler. 2007, 8, 300-304. [CrossRef]

17. Veldink, J.H.; Kalmijn, S.; Groeneveld, G.J.; Wunderink, W.; Koster, A.; de Vries, J.H.; van der Luyt, J.; Wokke, J.H.; Van den Berg, L.H. Intake of polyunsaturated fatty acids and vitamin E reduces the risk of developing amyotrophic lateral sclerosis. J. Neurol. Neurosurg. Psychiatry 2007, 78, 367-371. [CrossRef]

18. Mattson, M.P.; Cutler, R.G.; Camandola, S. Energy intake and amyotrophic lateral sclerosis. Neuromolecular Med. 2007, 9, 17-20. [CrossRef]

19. Dupuis, L.; Oudart, H.; Rene, F.; Gonzalez de Aguilar, J.L.; Loeffler, J.P. Evidence for defective energy homeostasis in amyotrophic lateral sclerosis: Benefit of a high-energy diet in a transgenic mouse model. Proc. Natl. Acad. Sci. USA 2004, 101, 11159-11164. [CrossRef]

20. Zhao, W.; Varghese, M.; Vempati, P.; Dzhun, A.; Cheng, A.; Wang, J.; Lange, D.; Bilski, A.; Faravelli, I.; Pasinetti, G.M. Caprylic triglyceride as a novel therapeutic approach to effectively improve the performance and attenuate the symptoms due to the motor neuron loss in ALS disease. PLoS ONE 2012, 7, e49191. [CrossRef] [PubMed]

21. Zhao, Z.; Lange, D.J.; Voustianiouk, A.; MacGrogan, D.; Ho, L.; Suh, J.; Humala, N.; Thiyagarajan, M.; Wang, J.; Pasinetti, G.M. A ketogenic diet as a potential novel therapeutic intervention in amyotrophic lateral sclerosis. BMC Neurosci. 2006, 7, 29. [CrossRef]

22. Wegorzewska, I.; Bell, S.; Cairns, N.J.; Miller, T.M.; Baloh, R.H. TDP-43 mutant transgenic mice develop features of ALS and frontotemporal lobar degeneration. Proc. Natl. Acad. Sci. USA 2009, 106, 18809-18814. [CrossRef]

23. Hatzipetros, T.; Bogdanik, L.P.; Tassinari, V.R.; Kidd, J.D.; Moreno, A.J.; Davis, C.; Osborne, M.; Austin, A.; Vieira, F.G.; Lutz, C.; et al. C57BL/6J congenic Prp-TDP43A315T mice develop progressive neurodegeneration in the myenteric plexus of the colon without exhibiting key features of ALS. Brain Res. 2014, 1584, 59-72. [CrossRef]

24. Rodriguez, A.; Ferrer-Donato, A.; Cabrera-Pinto, M.; Seseña, S.; Fernández, P.; Aranda, A.; Fernandez-Martos, C.M. Effect of ozone exposure on Amyotrophic Lateral Sclerosis (ALS) pathology using a mice model of TDP-43 proteinopathy. bioRxiv 2021. [CrossRef]

25. Fernandez, C.M.; Molto, E.; Gallardo, N.; del Arco, A.; Martinez, C.; Andres, A.; Ros, M.; Carrascosa, J.M.; Arribas, C. The expression of rat resistin isoforms is differentially regulated in visceral adipose tissues: Effects of aging and food restriction. Metabolism 2009, 58, 204-211. [CrossRef] [PubMed]

26. Livak, K.J.; Schmittgen, T.D. Analysis of relative gene expression data using real-time quantitative PCR and the 2(-Delta Delta C(T)) Method. Methods 2001, 25, 402-408. [CrossRef] [PubMed]

27. Ortega Moreno, L.; Sanz-Garcia, A.; Fernandez de la Fuente, M.J.; Arroyo Solera, R.; Fernandez-Tome, S.; Marin, A.C.; MoraGutierrez, I.; Fernandez, P.; Baldan-Martin, M.; Chaparro, M.; et al. Serum adipokines as non-invasive biomarkers in Crohn's disease. Sci. Rep. 2020, 10, 18027. [CrossRef]

28. Paganoni, S.; Deng, J.; Jaffa, M.; Cudkowicz, M.E.; Wills, A.M. Body mass index, not dyslipidemia, is an independent predictor of survival in amyotrophic lateral sclerosis. Muscle Nerve 2011, 44, 20-24. [CrossRef]

29. Esmaeili, M.A.; Panahi, M.; Yadav, S.; Hennings, L.; Kiaei, M. Premature death of TDP-43 (A315T) transgenic mice due to gastrointestinal complications prior to development of full neurological symptoms of amyotrophic lateral sclerosis. Int. J. Exp. Pathol. 2013, 94, 56-64. [CrossRef] 
30. Guo, Y.; Wang, Q.; Zhang, K.; An, T.; Shi, P.; Li, Z.; Duan, W.; Li, C. HO-1 induction in motor cortex and intestinal dysfunction in TDP-43 A315T transgenic mice. Brain Res. 2012, 1460, 88-95. [CrossRef]

31. Medina, D.X.; Orr, M.E.; Oddo, S. Accumulation of C-terminal fragments of transactive response DNA-binding protein 43 leads to synaptic loss and cognitive deficits in human TDP-43 transgenic mice. Neurobiol. Aging 2014, 35, 79-87. [CrossRef]

32. Munzberg, H.; Singh, P.; Heymsfield, S.B.; Yu, S.; Morrison, C.D. Recent advances in understanding the role of leptin in energy homeostasis. F1000Research 2020, 9. [CrossRef]

33. Zhou, Y.; Rui, L. Leptin signaling and leptin resistance. Front. Med. 2013, 7, 207-222. [CrossRef]

34. Tefera, T.W.; Borges, K. Metabolic Dysfunctions in Amyotrophic Lateral Sclerosis Pathogenesis and Potential Metabolic Treatments. Front. Neurosci. 2016, 10, 611. [CrossRef]

35. Tefera, T.W.; Steyn, F.J.; Ngo, S.T.; Borges, K. CNS glucose metabolism in Amyotrophic Lateral Sclerosis: A therapeutic target? Cell Biosci. 2021, 11, 14. [CrossRef]

36. Vandoorne, T.; De Bock, K.; Van Den Bosch, L. Energy metabolism in ALS: An underappreciated opportunity? Acta. Neuropathol. 2018, 135, 489-509. [CrossRef]

37. Blasco, H.; Lanznaster, D.; Veyrat-Durebex, C.; Hergesheimer, R.; Vourch, P.; Maillot, F.; Andres, C.R.; Pradat, P.F.; Corcia, P. Understanding and managing metabolic dysfunction in Amyotrophic Lateral Sclerosis. Expert Rev. Neurother. 2020, 20, 907-919. [CrossRef] [PubMed]

38. Shan, X.; Chiang, P.M.; Price, D.L.; Wong, P.C. Altered distributions of Gemini of coiled bodies and mitochondria in motor neurons of TDP-43 transgenic mice. Proc. Natl. Acad. Sci. USA 2010, 107, 16325-16330. [CrossRef] [PubMed]

39. Wang, W.; Li, L.; Lin, W.L.; Dickson, D.W.; Petrucelli, L.; Zhang, T.; Wang, X. The ALS disease-associated mutant TDP-43 impairs mitochondrial dynamics and function in motor neurons. Hum. Mol. Genet. 2013, 22, 4706-4719. [CrossRef] [PubMed]

40. Bejanin, A.; Tammewar, G.; Marx, G.; Cobigo, Y.; Iaccarino, L.; Kornak, J.; Staffaroni, A.M.; Dickerson, B.C.; Boeve, B.F.; Knopman, D.S.; et al. Longitudinal structural and metabolic changes in frontotemporal dementia. Neurology 2020, 95, e140-e154. [CrossRef] [PubMed]

41. Zhang, Y.; Chua, S., Jr. Leptin Function and Regulation. Compr. Physiol. 2017, 8, 351-369.

42. Cohen, S.; Danzaki, K.; MacIver, N.J. Nutritional effects on T-cell immunometabolism. Eur. J. Immunol. 2017, 47, 225-235. [CrossRef]

43. Lopez-Gomez, J.J.; Ballesteros-Pomar, M.D.; Torres-Torres, B.; De la Maza, B.P.; Penacho-Lazaro, M.A.; Palacio-Mures, J.M.; Abreu-Padin, C.; Lopez-Guzman, A.; De Luis-Roman, D.A. Malnutrition at diagnosis in amyotrophic lateral sclerosis (als) and its influence on survival: Using glim criteria. Clin. Nutr. 2021, 40, 237-244. [CrossRef] [PubMed]

44. Ludolph, A.C.; Dorst, J.; Dreyhaupt, J.; Weishaupt, J.H.; Kassubek, J.; Weiland, U.; Meyer, T.; Petri, S.; Hermann, A.; Emmer, A.; et al. Effect of High-Caloric Nutrition on Survival in Amyotrophic Lateral Sclerosis. Ann. Neurol. 2020, 87, 206-216. [CrossRef] [PubMed]

45. Holm, T.; Maier, A.; Wicks, P.; Lang, D.; Linke, P.; Munch, C.; Steinfurth, L.; Meyer, R.; Meyer, T. Severe loss of appetite in amyotrophic lateral sclerosis patients: Online self-assessment study. Interact. J. Med. Res. 2013, 2, e8. [CrossRef] [PubMed]

46. Ferri, A.; Coccurello, R. What is "Hyper" in the ALS Hypermetabolism? Mediat. Inflamm. 2017, 2017, 7821672. [CrossRef]

47. Pundir, C.S.; Narwal, V. Biosensing methods for determination of triglycerides: A review. Biosens. Bioelectron. 2018, 100, $214-227$. [CrossRef]

48. Lee, G.H.; Proenca, R.; Montez, J.M.; Carroll, K.M.; Darvishzadeh, J.G.; Lee, J.I.; Friedman, J.M. Abnormal splicing of the leptin receptor in diabetic mice. Nature 1996, 379, 632-635. [CrossRef]

49. Tartaglia, L.A.; Dembski, M.; Weng, X.; Deng, N.; Culpepper, J.; Devos, R.; Richards, G.J.; Campfield, L.A.; Clark, F.T.; Deeds, J.; et al. Identification and expression cloning of a leptin receptor, OB-R. Cell 1995, 83, 1263-1271. [CrossRef]

50. Varela, L.; Horvath, T.L. Leptin and insulin pathways in POMC and AgRP neurons that modulate energy balance and glucose homeostasis. EMBO Rep. 2012, 13, 1079-1086. [CrossRef]

51. Chiang, P.M.; Ling, J.; Jeong, Y.H.; Price, D.L.; Aja, S.M.; Wong, P.C. Deletion of TDP-43 down-regulates Tbc1d1, a gene linked to obesity, and alters body fat metabolism. Proc. Natl. Acad. Sci. USA 2010, 107, 16320-16324. [CrossRef] [PubMed]

52. Ohgomori, T.; Yamasaki, R.; Takeuchi, H.; Kadomatsu, K.; Kira, J.I.; Jinno, S. Differential activation of neuronal and glial STAT3 in the spinal cord of the SOD1(G93A) mouse model of amyotrophic lateral sclerosis. Eur. J. Neurosci. 2017, 46, 2001-2014. [CrossRef] [PubMed]

53. Ohgomori, T.; Yamasaki, R.; Kira, J.I.; Jinno, S. Upregulation of Vesicular Glutamate Transporter 2 and STAT3 Activation in the Spinal Cord of Mice Receiving 3,3'-Iminodipropionitrile. Neurotox. Res. 2018, 33, 768-780. [CrossRef]

54. Caron, A.; Dungan Lemko, H.M.; Castorena, C.M.; Fujikawa, T.; Lee, S.; Lord, C.C.; Ahmed, N.; Lee, C.E.; Holland, W.L.; Liu, C.; et al. POMC neurons expressing leptin receptors coordinate metabolic responses to fasting via suppression of leptin levels. Elife 2018, 7, e33710. [CrossRef] [PubMed]

55. Pedroso, J.A.; Silveira, M.A.; Lima, L.B.; Furigo, I.C.; Zampieri, T.T.; Ramos-Lobo, A.M.; Buonfiglio, D.C.; Teixeira, P.D.; Frazao, R.; Donato, J., Jr. Changes in Leptin Signaling by SOCS3 Modulate Fasting-Induced Hyperphagia and Weight Regain in Mice. Endocrinology 2016, 157, 3901-3914. [CrossRef] [PubMed]

56. Clark, C.M.; Clark, R.M.; Hoyle, J.A.; Dickson, T.C. Pathogenic or protective? Neuropeptide Y in amyotrophic lateral sclerosis. J. Neurochem. 2021, 156, 273-289. [CrossRef] 
57. Vercruysse, P.; Sinniger, J.; El Oussini, H.; Scekic-Zahirovic, J.; Dieterle, S.; Dengler, R.; Meyer, T.; Zierz, S.; Kassubek, J.; Fischer, W.; et al. Alterations in the hypothalamic melanocortin pathway in amyotrophic lateral sclerosis. Brain 2016, 139, 1106-1122. [CrossRef]

58. Butti, Z.; Patten, S.A. RNA Dysregulation in Amyotrophic Lateral Sclerosis. Front. Genet. 2018, 9, 712. [CrossRef]

59. Xue, Y.C.; Ng, C.S.; Xiang, P.; Liu, H.; Zhang, K.; Mohamud, Y.; Luo, H. Dysregulation of RNA-Binding Proteins in Amyotrophic Lateral Sclerosis. Front. Mol. Neurosci. 2020, 13, 78. [CrossRef] 